\title{
Exploring Student Perceptions of the Influence of Action Learning Sets, for Large Lecture Groups, on Engagement with Learning.
}

(Q) University of Worcester

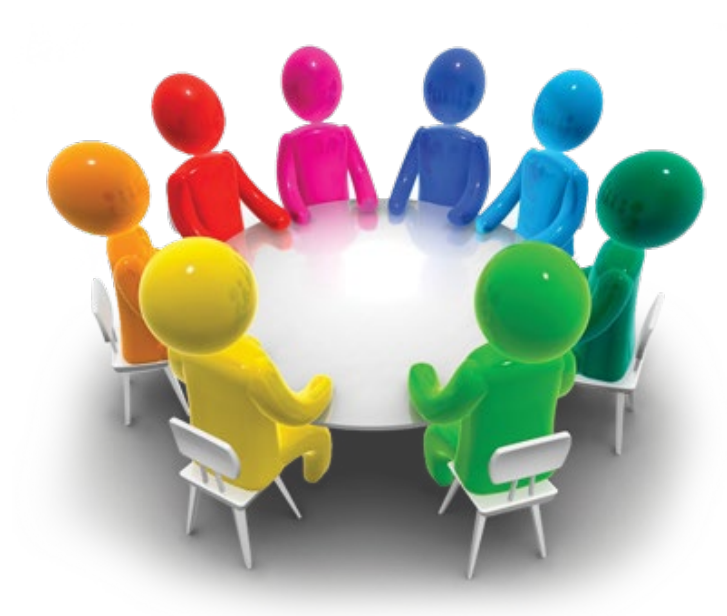

Karen Williams

Senior Lecturer

School of Sport \& Exercise Science 
"The engagement of larger cohorts can be seen as a challenge for even the most experienced practitioners in Higher Education" (Purcell 2011, p1).

Not new concerns, studies suggest this has been a topical area for over a decade (Gibbs 1992, Biggs 1999).

Student engagement is weakened by large lecture groups and the relationship between lecturers and students may be compromised (Gibbs 1992). of Worcester

\begin{tabular}{|c|}
\hline Students \\
expressed the \\
difficulty in \\
hearing content \\
and being able to \\
engage in mid- \\
module \\
evaluations.
\end{tabular}

\section{Context}

Third year module with 91 students.
Lecturer observations of sessions indicated students talking, on phones, laptops, lack of interaction resulting in nonactive participants

(Biggs 1999). 


\section{What was the intervention?}

\section{Issue:}

Concerns over engagement and how to personalise learning for students in large lectures.

\section{Strategy:}

In response to student feedback Action Learning Sets (ALS) were introduced by the module team in February 2018.

How can I
check \&
ensure
learning takes
place?

How can I
engage more
students and
get them to
interact more?

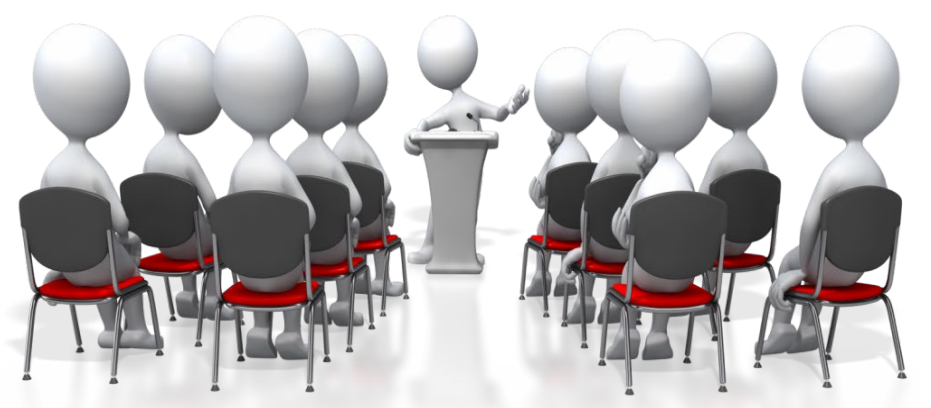

$\downarrow$
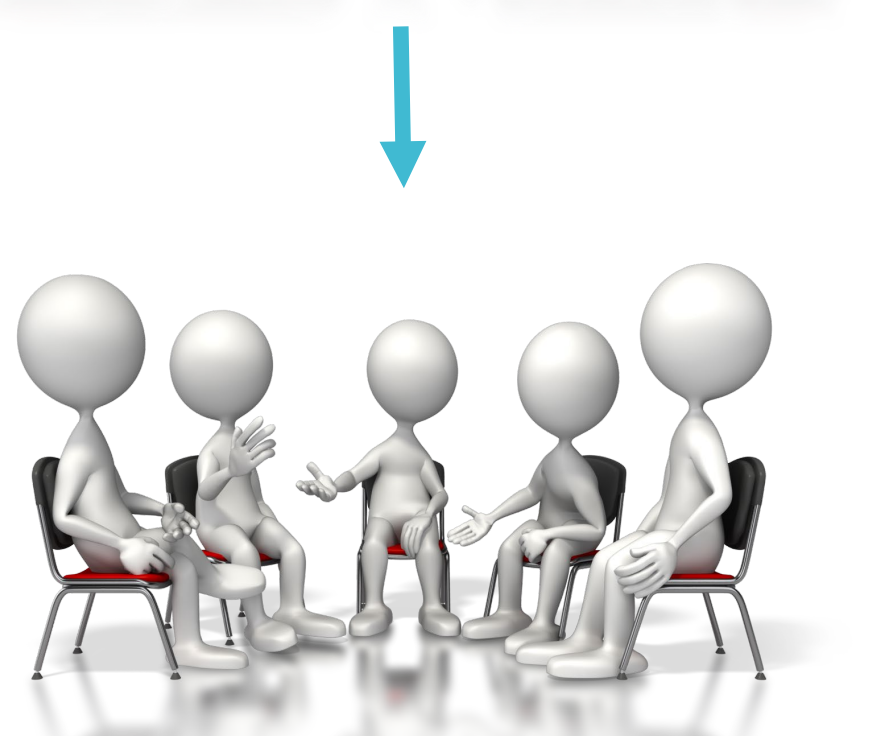

The notion of ALS as a tool of delivery aimed to facilitate student involvement and active learning.

Offering a
collaborative
platform for students
to reflect on their
experience and learn
from others (Head
and McGill 2002).




\section{Implementing the change...}

Action Learning was first introduced by Revens in the early 1980's who was seen as the founder of this type of activity whereby knowledge and subsequent learning was gained through reflecting on actions and looking for future actions (Weinstein 1999, Maddison and Strang 2018).
Prepared pre-lecture material on blackboard.
Discussion of key aspects, based on the topic, to create a deeper level of learning.

Sharing of learner experiences on placement. 


\section{Action Research Project}

Research that will help the practitioner, which can result in improved action in practice and enables teachers to create several questions from within their own practice (Baumfield, Hall and Wall 2013, p3).

To determine student perceptions of the Action Learning Sets in terms of their engagement in the sessions.

Aims

\&

Objectives
Form a comparison between the views of their own engagement since the intervention began and now using Action Learning Sets.

- The secondary aim is to identify the worth of this intervention, to inform my own future practice on how to engage large cohorts of Higher Education students. 


\section{Methodology}

\section{Action Research}

Gaining student perceptions

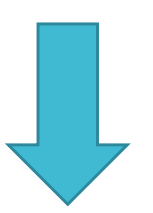

\section{Questionnaires:}

Likert/Open-

ended questions 23/36 returned
Data Analysis:

Percentages /

Thematic Analysis

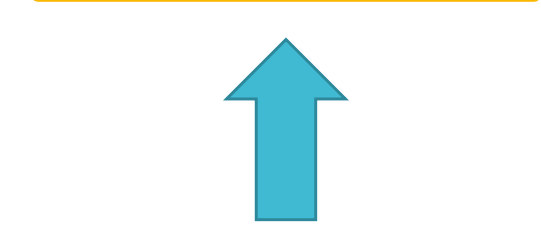

Observation:

PG Cert tutor

Focus on

Engagement

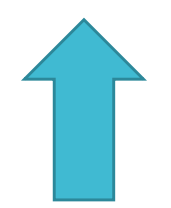

\section{Focus Groups:}

$2 \times 6$ students

3 key questions-

10 minutes each 


\section{3/36 responses:}

Strongly Agree (SA) Agree (A) Disagree (D) Strongly Disagree (SD) Action Learning Sets (ALS)

$100 \%$ of students felt they understood the content (Q1 SA,69.6\%; A, 30.4\%) land had more focus in the module (Q2 SA,73.9\%; A, 26.1\%) through ALS.

$100 \%$ of students felt more confident to contribute (Q4 SA,78.3\%; A, 21.7\%) and to ask questions (Q5 $\mathrm{SA}, \mathbf{6 9 . 6 \%} \mathrm{A}, \mathbf{3 0 . 4 \% )}$ in the ALS.

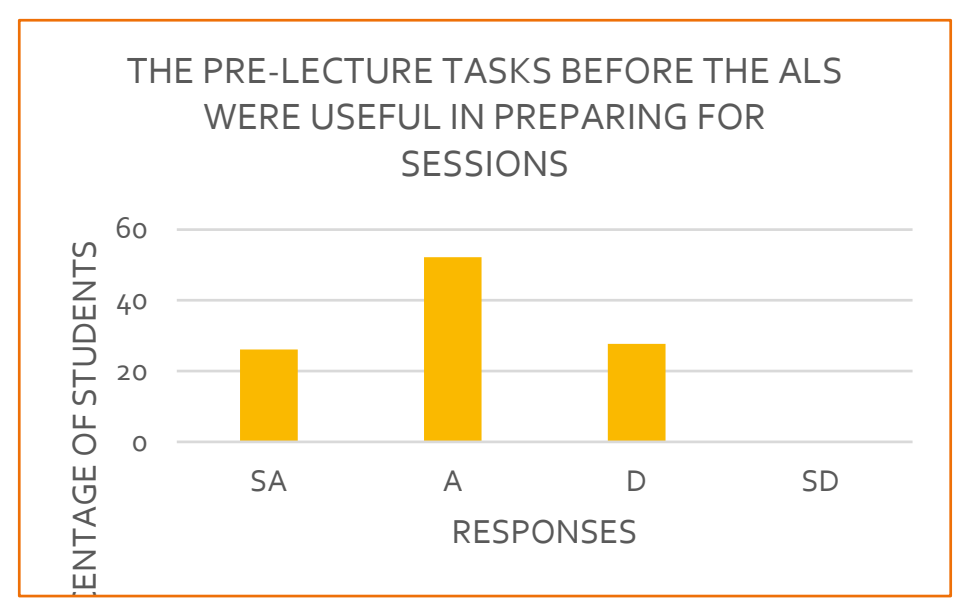

Q1 I FOUND LEARNING IN SMALLER

ALS ALLOWED ME TO FOCUS MORE IN THE MODULE.

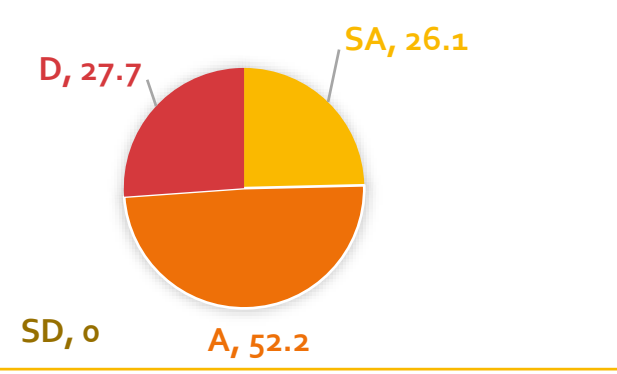

SD, 0

A, 52.2

Q4 I AM ABLE TO CONTRIBUTE MORE

TO THE SESSIONS IN ALS

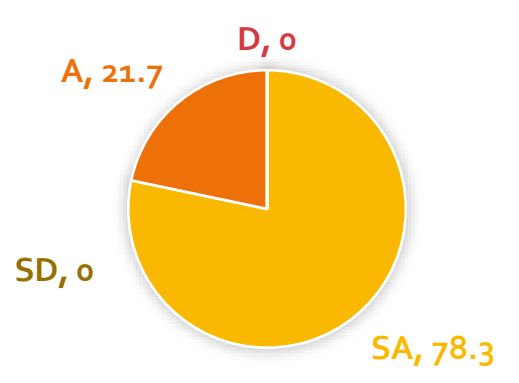

Q2 I HAVE UNDERSTOOD THE CONTENT OF THE LECTURES MORE THROUGH ALS

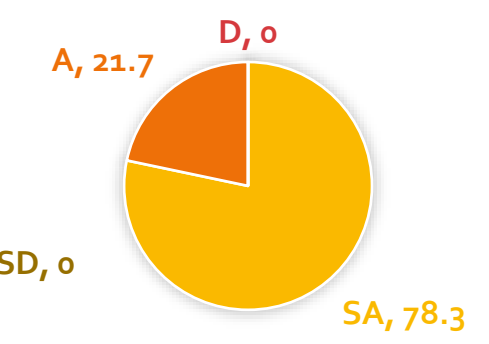

$\mathrm{O}_{5}$ I FEEL CONFIDENT TO ASK MORE QUESTIONS IN ALS

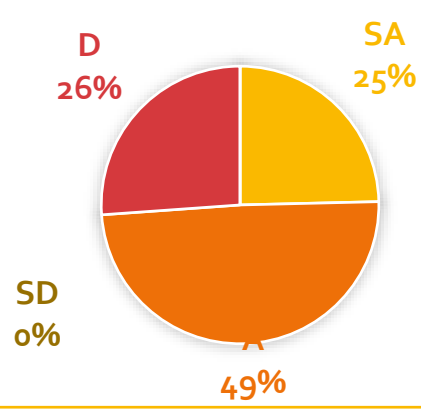

$78 \%$ of students felt the pre-lecture tasks were useful in preparing for the ALS (Q3 SA,26.1\%; A, 52.2\%) however $22 \%$ disagreed with this statement (Q3 D, 21.7\%). 


\section{Positive comments -open-ended questions;}

"As a smaller group it was more contact time with lecturer, meaning I was more engaged and asking questions".

"I feel very engaged with the ALS due to smaller grouping and questions aimed for individuals specifically".

"I feel we have covered more areas and been able to gain valuable knowledge on the practical aspects of teaching which would not have in the larger classes...it was easier to 'make friends' and learn from others in the ALS".
Negative comments -open-ended questions;

"Although I think the ALS are better than whole group lectures, they were very rushed. Often there was not enough time to cover all the content let alone time for questions and clarifications".

"I think the sessions would have been better if two groups were joined to allow more time".

"My engagement is good regardless of the setting". 


\section{Areas of good practice to develop and disseminate:}

- Use of ALS's to support and engage students in the leaning and assessment process. This approach proved to be extremely beneficial and successful with this group of students.

- All students were fully engaged with the content and assessment of the session. Students all had and took advantage of the opportunity to participate in the ALS and learn from it.

- Your very good levels of subject knowledge.

\section{Areas which could be the focus for further development:}

Drawing upon research and literature base in ALS:

- Draw upon one or two modelled paragraphs for the assignment which incorporate critique and use of literature for the higher marks.

- It would be useful to refer to a few of the key theorists / literature both learning theorists and PE specific research / positions. 
1) Higher engagement levels in ALS compared to large lectures.

3 KEY QUESTIONS - (10 minutes):

What has been the impact of ALS to your learning and engagement?

What are your opinions on ALS as a tool for learning lecture content?

Have there been any other benefits or limitations from studying in ALS?
2) Limitations of time \& value of pre-lecture tasks.

3) Opportunities for students to collaborate and learn from each other.

4) Student-lecturer communications and connections.

5) Improved knowledge and understanding of assessment and therefore attainment. 


\section{Conclusions \& recommendations.}

Findings suggest that the introduction of ALS was a positive intervention that enhanced student engagement.

ALS were a useful tool to address the challenges faced when teaching large groups.

ALS had a positive impact on students understanding of assessment.

\section{If you were to consider the use of Action Learning Sets in your own practice you might consider the following areas;}

Useful for all sizes of group.

Staff deployment, preparation time and consistency.

ALS need to be managed correctly- time factor, expectations.

Embedding research to secure knowledge and maintain high academic quality in delivery.

Ensure there is the element of independence- value in completing pre-lecture tasks. 


\section{Impact on my own professional development}

Utilising University policies in course and curriculum design.

* Understanding the importance of student voice as a tool for change and making that change \& the value of actionresearch on my own practice- deeper reflection and evaluation.

Embedding teaching philosophy and values- there are ways to cater for all students despite the large numbers and offer a personalised approach to lecturing.

Enhancing the academic rigour and developing its application to teaching practice.

The significance of improved lecturer - students rapport and communication. 


\section{Further impact and future study}

$>$ Complete on a larger scale- is my group a true representation of the perspectives of all students?

Indications from module information and assessment grades show a positive correlation between ALS and attendance and ALS and attainment: could be an area in which to develop the next phase of the Action Learning Cycle.

$>$ Changes made: Longer sessions and slightly larger groups sizes.

Early module health checks January 2019: indicated students were finding the ALS valuable and found the time allocated for the sessions suitable and the group sizes worked well.

End of module evaluations: $100 \%$ satisfaction on the module with a range of comments that suggested the smaller group seminars (ALS style sessions) were positive, helpful and more personalised. 


\section{Key References:}

Baumfield, V., Hall, E., and Wall, K. (2013) Action Research in Education. $2^{\text {nd }}$ Ed. London: Sage Publications

Biggs, J. (1999). Teaching for quality learning at university: What the student does, Buckingham: Open University Press.

Carini, R,M., Kuh, G,D., and Klein, S, P. (2006) 'Student engagement and student learning: Testing the linkages', Research in Higher Education, 47(1), pp.1-32.

Cohen, L., Manion, L, and Morrison, K. (2000) Research Methods in Education. London: Routledge Falmer

Gibbs, G. (1992). 'Control and independence'. in Gibbs, G. and Jenkins, A. (eds.) Teaching large classes in higher education: How to maintain quality with reduced resources. London: Kogan, pp. 37-59.

Kinsella, G.K., Mahon, C., and Lillis, S. (2017) 'Using pre-lecture activities to enhance learner engagement in a large group setting', Active Learning in Higher Education, 18(3), pp. 231-242. doi: $10.1117 / 14697874177 / 5205$

Taylor, C., Wilke, M., Baser, J. (2008) Doing Action Research: A Guide for School Support Staff. London: Sage Publications 